\title{
Using alternative fuels to increase energy efficiency in the transport sector
}

\author{
Olga Gamayunova, ${ }^{1, *}$, and Kirill Kulakov ${ }^{2}$ \\ ${ }^{1}$ Peter the Great St. Petersburg Polytechnic University, Polytechnicheskaya, 29, St.Petersburg, \\ 195251, Russia \\ ${ }^{2}$ Moscow State University of Civil Engineering, Yaroslavskoe shosse, 26, Moscow, 129337, Russia
}

\begin{abstract}
The trend of recent years is the constant increase in fuel consumption by transport. Transport is the most important consumer of the highest quality types of liquid fuel, a large consumer of electricity. The article describes the main types of alternative fuel, the advantages of replacing gasoline with natural gas, evaluates the economic efficiency of conversing a car to gas and proposes general measures for energy conservation and energy efficiency in the transport sector.
\end{abstract}

\section{Introduction}

The energy intensity of Russian GDP is currently several times higher than the global average. This can be explained by the harsh climate, but the energy intensity of the GDP of countries located in similar geographical and climatic conditions, such as Finland, Canada, and the Scandinavian countries, is on average 2 times lower than the national one (see Fig. 1). Therefore, the issue of energy efficiency and energy saving for Russia has a high degree of relevance.

According to the increase in energy consumption, transport takes the second place after industry. The main reason for the rapid growth is the increase in liquid fuel con-sumption in personal automobile transport.

Improving the energy efficiency of road transport can be achieved through measures such as: reducing the weight of cars through the replacement of metal materials with polymer materials, the use of alternative fuels, improving the quality of roads by using modern materials for road construction, etc.

\section{$2 \quad$ Alternative fuels}

\subsection{Biofuel}

Biofuels are obtained from plant or animal raw materials, from human and animal waste products or organic industrial waste. The world's first biofuel for automobiles was a

*Corresponding author: gamayunova_os@spbstu.ru 
mixture of diesel fuel and rapeseed oil (its share ranged from 5 to 30 percent). The main biofuel production technologies described below (see Fig. 2).

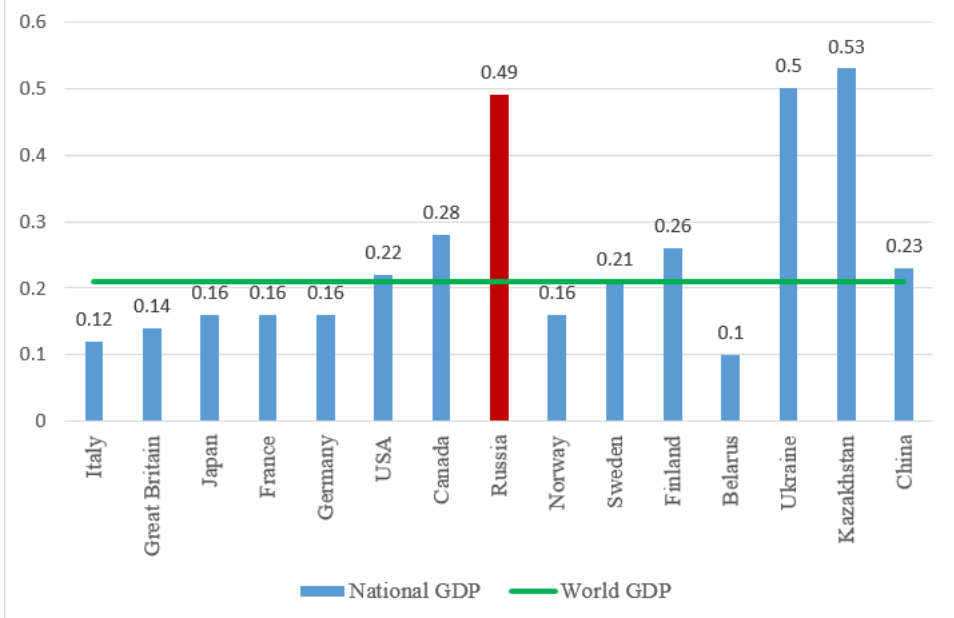

Fig. 1. Energy intensity of GDP in various countries and the world (in kilograms of oil equivalent per US dollar)

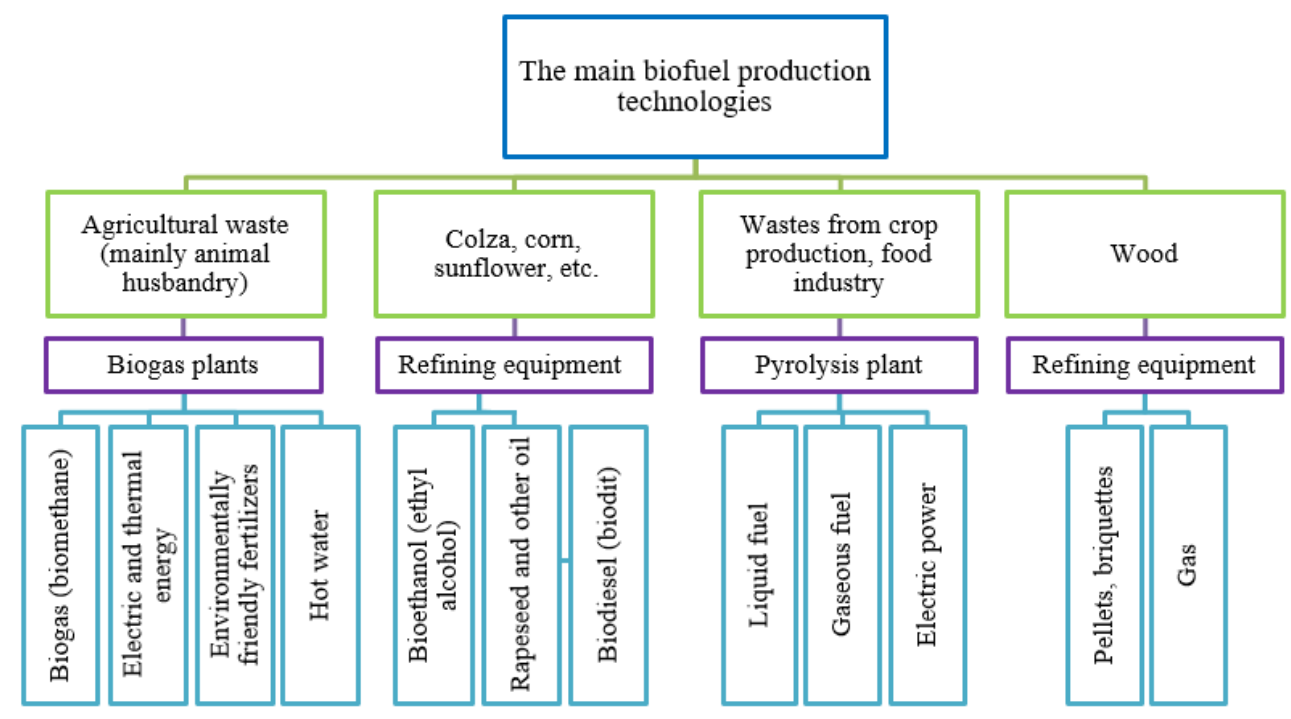

Fig. 2. The main biofuel production technologies

\subsection{Hydrogen}

Hydrogen $\left(\mathrm{H}_{2}\right)$ is an alternative fuel that is obtained from hydrocarbons, biomass, and garbage. Some automakers, for example, BMW, Mazda, Toyota, etc. (see Fig. 3) are trying to use hydrogen as fuel for the engine. The idea is really attractive: firstly, hydrogen is the most common element in the Universe, and secondly, when it is burned, only water is formed! In addition, no carbon dioxide and toxic substances. 


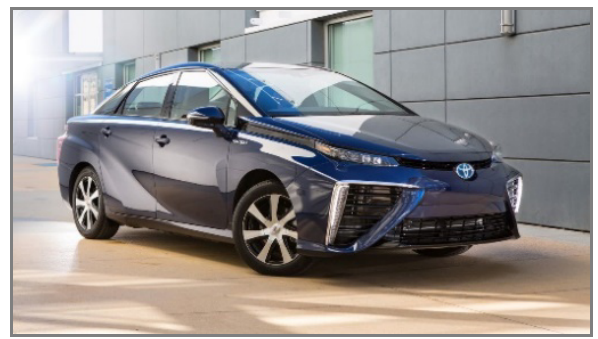

a)

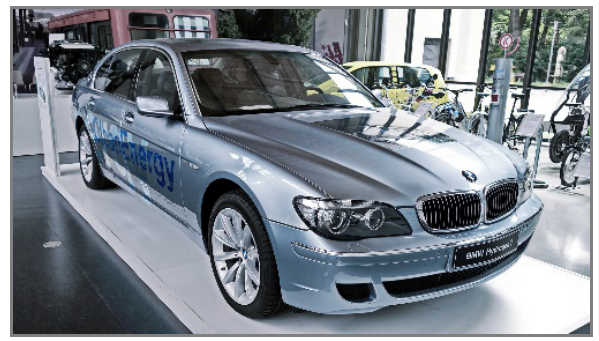

b)

Fig.3. Cars powered by hydrogen (a - Toyota Mirai, b - BMW Hydrogen 7)

\subsection{Electricity}

Electricity can be used as an alternative type of fuel for vehicles powered by batteries, or powered by fuel cells. Battery powered electric vehicles accumulate energy in batteries that are charged by connecting the vehicle to a standard power source. Fuel cell vehicles operate on electrical energy, which is generated by an electrochemical reaction that occurs when hydrogen and oxygen combine. Fuel cells produce electricity without internal combustion and environmental pollution.

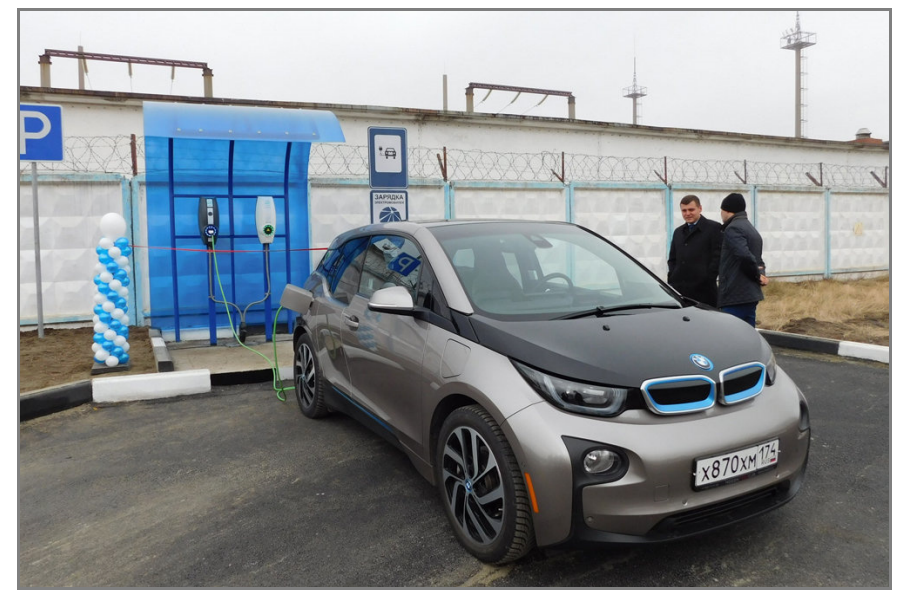

Fig. 4. Electric filling station (Russia, Chelyabinsk region, Yuzhnouralsk).

In recent years, there have been many electric vehicles that have marked significant progress in this area: engines add to power, while cars becoming more compact. Almost every major automaker has in its model range an electric car: Tesla Model S, MercedesBenz EQC, Chevrolet Spark EV, BMW i3, Porsche Panamera S Hybrid E, etc. The main obstacle to the spread of electric vehicles is still the insufficient capacity of electric power sources. However, gas stations for electric vehicles are already available (see Fig. 4).

\section{Petrol substitution with natural gas}

The current level of development of science and technology makes it possible to more widely introduce gas fuel in road transport. Components of gas equipment have a higher service life (up to 25 years) and reasonable prices, compared with the fuel equipment of engines using oil fuel. 
According to the GlobalPetrolPrices.com resource, which tracks fuel and electricity prices in more than 100 countries, the cost of energy resources looked as follows (see Fig. 5).

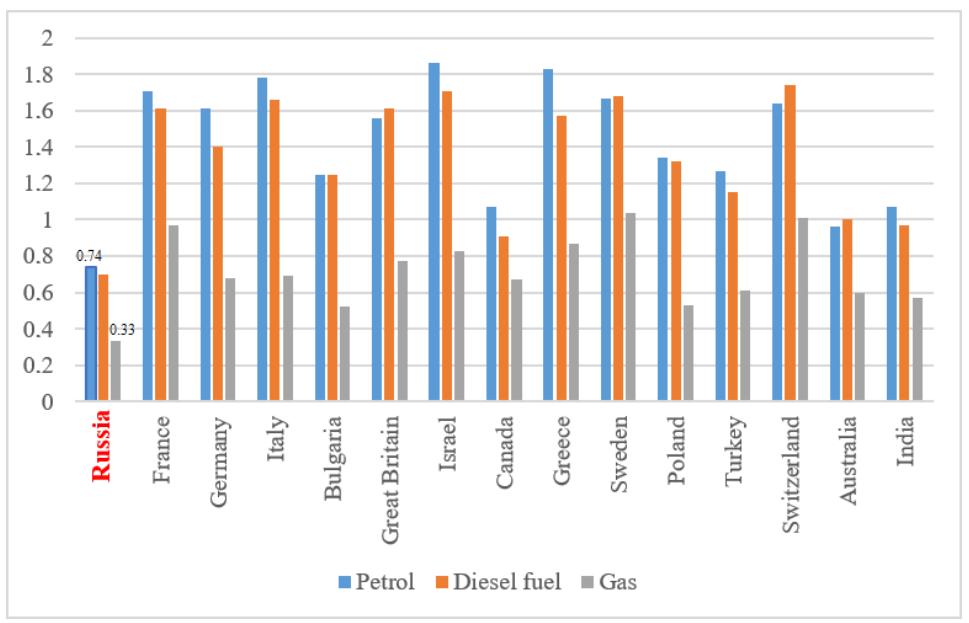

Fig. 5. Cost of energy resources (liter, U.S. Dollar)

There is a significant difference in fuel prices between different countries. As a rule, rich countries have higher prices, while poor countries and countries that produce and export oil have significantly lower prices. The one exception is the United States, an economically developed country with low petrol prices. The difference in prices in different countries is due to different taxes and subsidies on petrol. All countries have access to oil in international markets, but they have different taxes. As a result, petrol prices are different.

Benefits of using gas:

- Environmental friendliness. Emissions of carbon monoxide and hydrocarbons are reduced.

- Efficiency of use. The boiling point of propane is less than diesel fuel and gasoline, which allows for complete combustion of fuel without the use of evaporation equipment and mixing with air.

- Multipurpose use. Liquefied gas is suitable for the operation of equipment other than cars.

- Profitability. The use of gas gives less wear on the engine and reduces the cost of major repairs.

- Security. Propane and other types of liquefied gas have a lower flash point than gasoline. Therefore, it is safer to store, transport and fill them in gas cylinders of cars.

- Cost. Filling with liquefied gases is cheaper, even if we take into account a slightly higher fuel consumption.

\section{Calculation of the economy of converting a car to gas}

Converting the car to gas will make it bi-fuel - you can refuel with petrol and gas at the same time. But gas is two times cheaper. We will calculate the savings in convert-ing a car to gas using the Kia Picanto III hatchback (2007, A-class, front-wheel drive, mechanics and automatic, petrol engines with power from 67 to 100 horsepower). For calculation (see Table 1-3), we will accept the price of gasoline as 0.74 USD, the cost of gas - 0.33 USD (Fig.5). 
Table 1. Kia Picanto III petrol costs

\begin{tabular}{llllll}
\hline Volume & Transmission & Type of petrol & City mode & Highway mode & Mixed mode \\
\hline 1.0 & Mechanics & 95 & 5.6 & 3.7 & 4.4 \\
1.2 & Mechanics & 95 & 5.9 & 3.5 & 4.6 \\
1.2 & Automatic & 95 & 7.0 & 4.5 & 5.4 \\
\hline
\end{tabular}

Table 2. Kia Picanto III gas costs

\begin{tabular}{llllll}
\hline Volume & Transmission & Type of gas & City mode & Highway mode & Mixed mode \\
\hline 1.0 & Mechanics & & 6.2 & 4.1 & 4.8 \\
1.2 & Mechanics & liquefied & 6.5 & 3.9 & 5.1 \\
1.2 & Automatic & petroleum gas & 7.7 & 5.0 & 5.9 \\
\hline
\end{tabular}

Table 3. Kia Picanto III petrol and gas costs, savings

\begin{tabular}{lllll}
\hline Volume & Transmission & $\begin{array}{l}\text { 1000 km petrol refueling, } \\
\text { mixed mode }\end{array}$ & $\begin{array}{l}1000 \mathrm{~km} \text { gas } \\
\text { refueling, mixed mode }\end{array}$ & Remainder \\
\hline 1.0 & Mechanics & 32.6 & 15.8 & 16.7 \\
1.2 & Mechanics & 34.0 & 16.8 & 17.2 \\
1.2 & Automatic & 40.0 & 19.5 & 20.5 \\
\hline
\end{tabular}

\section{Conclusions}

Road transport spends more than half of the total energy consumed by all modes of transport. The main areas of energy conservation in road transport are:

- increasing the share of freight and passenger traffic carried out by cars and buses with diesel engines (dieselization);

- a decrease in specific fuel consumption rates for automobiles by increasing the efficiency of engines and transmissions,

- reducing their own mass of cars and aerodynamic drag,

- increasing the share of radial tires; equipping vehicles with motion detection devices;

- replacing gasoline with less scarce fuels, primarily compressed and liquefied gas.

In total, all these factors give a double (or more) cost savings on fuel, extend the life of the engine by $30-40 \%$, oil and spark plugs by half, and, as a result, significantly reduce not only operational, but also repair costs.

\section{References}

1. S. Vysotskiy, N. Stolyarova, S. Kuzmina, Energosberezheniye 9, 6-9, (2012).

2. Yu. Lazarev, Technical and technological problems of service 1 (43), 61-65, (2018).

3. N. Sevryugina, M. Stepanov, Magazine of Civil Engineering 7 (75), 23-36, (2017).

4. M. Telegina, A. Barabash, E.Naumova, O. Zhuvak, Yu. Lazarev, Construction of Unique Buildings and Structures 11 (62), 71-82, (2017).

5. Automotive gas fuel systems, https://agts.ru/i/rashod, last accessed 2019/08/16.

6. A. Tsal, N. Ermoshin, P. Sereda, Inzhenernyy vestnik Dona 1 (48), 139, (2018).

7. Yu. Lazarev, N. Ermoshin, Technical and technological problems of service 1 (39), 58-62, (2017). 